\title{
microRNAs in esophageal cancer (Review)
}

\author{
BIN HE, BANGLIANG YIN, BAOXIANG WANG, ZHENKUN XIA, CHEN CHEN and JINGQUN TANG
}

\author{
Department of Cardiothoracic Surgery, the Second Xiangya Hospital of \\ Central South University, Changsha, Hunan 410011, P.R. China
}

Received March 24, 2012; Accepted June 22, 2012

DOI: $10.3892 / \mathrm{mmr} .2012 .975$

\begin{abstract}
Esophageal cancer (EC) is one of the most common malignant tumors worldwide. EC is usually diagnosed at a locally advanced stage or at a stage with involvement of lymph nodes. Despite aggressive treatment, the overall five-year survival rate remains poor. microRNAs (miRNAs) are small, non-coding endogenous RNAs that negatively regulate gene expression at the post-transcriptional and/or translational level. Accumulating evidence suggests that the deregulation of miRNAs not only results in cancer progression, but also directly promotes tumor initiation. Previous studies found that miRNAs are frequently deregulated in EC, indicating that miRNAs are important in tumorigenesis. In this review, we summarize therecently recognized miRNA expression and its impact on the biology of EC and the potential applications for EC.
\end{abstract}

\section{Contents}

1. Introduction

2. miRNA synthesis and biological properties

3. miRNAs as tumor suppressor genes

4. miRNAs as oncogenes

5. miRNAs in EC

6. miRNAs serving as diagnostic and prognostic biomarkers in EC

7. The role of miRNAs in invasion and metastasis of EC

8. The role of miRNAs in the growth of EC

9. Single nucleotide polymorphisms of miRNAs in EC

10. The roles of epigenetic regulation of miRNAs in EC

11. The role of miRNAs in treatment of EC

12. Conclusion

Correspondence to: Dr Jingqun Tang, Department of Cardiothoracic Surgery, the Second Xiangya Hospital of Central South University, 139 Middle Renmin Road, Changsha, Hunan 410011, P.R. China

E-mail: sy99426@sina.com

Key words: esophageal cancer, microRNAs, deregulation, dysfunction, tumorigenesis

\section{Introduction}

The incidence and mortality of esophageal cancer (EC) are high, and rank eighth and sixth, respectively, out of all types of cancer, affecting more males than females (1). Esophageal squamous cell carcinoma (ESCC) and adenocarcinoma (EAC) are the two main subtypes of EC in terms of pathological characteristics. ESCC remains the dominant subtype of EC. EC is usually diagnosed at an advanced stage or with lymph node metastases. Due to the potential characteristics of invasion and metastasis in esophageal carcinoma cells, which are important prognostic factors, the overall 5-year survival rate is poor despite advanced treatment $(1,2)$. Improved understanding of the biological behavior in EC is important for the development of new therapeutic strategies and diagnostic methods.

microRNAs (miRNAs) are non-coding single-stranded, endogenous RNA molecules, approximately 21-25 ribonucleotides in length and highly conserved in evolution, which negatively regulate gene expression at the post-transcriptional and/or translational level. miRNAs are important in diverse biological processes including development, cell differentiation, proliferation, apoptosis, hormone secretion, tumor formation and drug resistance (3-5). Experimental evidence revealed that the majority of human miRNA genes are located at fragile sites and genomic regions involved in cancer, functioning as oncogenes or tumor suppressor genes (6-8). In this review, we aim to summarize the recognized miRNAs that play roles in the development of EC and the mechanism by which miRNAs are involved in EC.

\section{2. miRNA synthesis and biological properties}

miRNAs form clusters transcribed as polycistronic transcripts by RNA polymerase II and/or III, which undergo sequential steps of maturation. Clustered miRNAs may be transcribed from a single transcription unit as polycistronic primary-miRNAs (pri-miRNAs), which have the cap structure (7MGpppG) and polyadenylation tail (polyA tail). The pri-miRNAs are processed in the nucleus into pre-miRNAs by the microprocessor complex, which consists of the RNase III endonuclease Drosha and its cofactor, the double-stranded RNA binding protein Pasha/DGCR8. The pre-miRNAs are approximately 70 nucleotides in length, and are then transported into the cytoplasm by Ran-GTP and Exportin 5 . The cytoplasmic RNase III Dicer cleaves pre-miRNA into double-stranded RNA, which is 21-25 nucleotides in length. 
The double-stranded RNA is unwound to produce singlestranded miRNA in the RNA-induced silencing complex (RISC), where the mature miRNAs and its target mRNA interact (9-17). The miRNA gene mutations, translocations or impaired biosynthesis processes lead to changes in the miRNA expression level.

In 1993, the first miRNA was discovered through the study of the heterochronic gene lin-14 in worms, which was designated as lin-4 (18). Over 1000 miRNAs have been identified in animal genomes through cloning and bioinformatics techniques, approaching approximately $3 \%$ of all human protein-coding genes and controlling a wide range of gene regulatory networks (19). Therefore, the dysregulation of miRNAs may contribute to the initiation and development of cancer.

\section{3. miRNAs as tumor suppressor genes}

miRNAs functioning as tumor suppressor genes often have low expression in tumors, whereas target genes are highly expressed. For example, the miR-15a and miR-16a clusters at chromosome 13q14 were deleted or downregulated in many adult B-cell chronic lymphocytic leukemia patients. The anti-apoptotic factor BCL2, which is target of miR-15a and miR-16a, was negatively regulated by these two miRNAs; therefore, miR-15a and miR-16a downregulation could result in higher BCL2 protein levels and anti-apoptotic activity $(20,21)$. Another important suppressive miR is let-7, which was generally downregulated in lung cancer tissue while the let-7 expression level was positively correlated with the prognosis of patients. However, let-7 overexpression significantly inhibited tumor cell growth in the lung cancer cell line A549, indicating that let-7 plays a role in the development of lung cancer $(22,23)$. Downregulation of miR-29b was also reported in the KMCH cell line of bile duct cell carcinoma and 1/3 of human cholangiocarcinoma, while myeloid leukemia-1 (Mcl-1), its target gene, was overexpressed, ultimately resulting in suppressed apoptosis of cholangiocarcinoma cells (24). miR-122 was reported to have suppressive roles by negatively regulating cyclin G1 and reducing proliferation and inducing apoptosis in vitro (25). The genetic region containing miR-34a is often deleted in many tumors, and other studies have found that the p53-dependent inhibition of miR-34a induced the overexpression of BCL2, resulting in the inhibition of apoptosis and cell proliferation $(26,27)$. A similar situation was applied to miR-205, which was reported to directly target ErbB3 and vascular endothelial growth factor A (VEGF-A), which reduced the level of ErbB3 protein, acting as a potential tumor suppressor by inhibiting proliferation (28).

\section{4. miRNAs as oncogenes}

As miRNAs negatively regulate gene expression at the post-transcriptional and/or translational level, changes of the expression level of these miRNAs can be tumorigenic, as well as oncogenic. Typical examples are miR-17-92, which is located at 13q31-32, a region commonly amplified in B-cell lymphoma, and usually upregulated. This gene contributes to the development of the tumor by affecting the cell cycle, apoptosis, angiogenesis and metastasis, which suggests that miR-17-92 may act as an oncogene (oncomiRNA) by regulating the transcription factor E2F1 protein and myc protein (29-34). The dysregulation of miRNAs may be involved in cancer progression. Overexpression of miR-21 was found to be involved in cell differentiation, proliferation and apoptosis in various tumor types, and therefore miR-21 functions as an oncogene by directly downregulating the tumor suppressor gene tropomyosin 1 (TPM1) (35). The role of miR-10b as an oncogene in lung cancer was supported by experiments showing that the expression of miR-10b was significantly higher following induction of the transcription factor Twist, and this resulted in the target gene HOXDIO of miR-10b being downregulated and the expression of transfer-related protein RHOC being upregulated (36). With the rapid development of miRNA detection technology, a better understanding of the roles of miRNAs in the progression of cancer is likely to improve our knowledge of the pathogenesis of cancer, serving in molecular diagnosis, risk assessment and therapeutic approaches for cancer in the future.

\section{5. miRNAs in EC}

Esophageal carcinogenesis is a multi-stage process, involving a variety of changes in gene expression and DNA structure. miRNAs are efficient regulators of gene expression that are important in the initiation and progression of a variety of tumors, including EC. miRNA expression profiles performed by miRNA array are capable of distinguishing esophageal tumor histologies and discriminating normal tissue from tumor tissue. miRNA expression is also useful for identifying Barrett's esophagus (BE) patients at high risk of progression to adenocarcinoma (AC) (37).

\section{6. miRNAs serving as diagnostic and prognostic biomarkers in $\mathrm{EC}$}

The overall prognosis of EC is poor despite advanced treatment. The identification of new diagnostic and prognostic biomarkers are crucial in the clinic and for treatment of the disease. Due to the important regulatory roles of miRNAs in the initiation and progression of cancer and their high tissue specificity, miRNAs may be potential biomarkers for diagnosis, prognosis and prediction of response to therapy in EC.

Guo et al found aberrant expression of 46 miRNAs in EC tissues, of which 7 miRNAs (upregulation of miR-25, miR-424 and miR-151; downregulation of miR-100, miR-99a, miR-29c and miR-140) can be used as biomarkers to distinguish malignant EC lesions from adjacent normal tissue. Moreover, miR-335, miR-181d, miR-25, miR-7 and miR-495 were associated with the general pathological type of EC (fungating vs. medullary); miR-25 and miR-130b were associated with the degree of differentiation of $\mathrm{EC}$ and the expression level of miR-103/107 was negatively correlated with the survival rate of EC patients and may be used for early diagnosis as well as gene therapy targets for EC (38). The expression of certain miRNAs showed pathological cell type specificity. By analyzing the expression of miRNAs in EC, Feber $e t$ al found that miR-203 and miR-205 were downregulated compared with normal epithelium in EC, while miR-21 was overexpressed in the two types of EC. miR-200c, miR-194 and miR-192 were shown to be downregulated in ESCC, but were significantly 
upregulated in EAC (37). Mathé et al (39) have demonstrated that the overexpression of miR-21 in non-cancerous tissue of ESCC and downregulation of miR-375 in cancerous tissue of EAC with BE were markedly associated with worse prognosis. miR-196a was highly expressed in EAC, BE, benign and malignant junctions and highly malignant tissue and may be used as a biomarker for screening EC (39-41). Among others, the overexpression of miR-129 was identified as a significant and independent prognostic factor in surgically treated ESCC patients (42). The expression level of miR-1322 was higher in ESCC tissue and was able to distinguish ESCC samples from healthy samples (43). miR-31 and miR-142-3p expression were correlated with histological differentiation, and a high miR-142-3p expression was associated with a poor prognosis and may be identified as a potential independent prognostic factor in ESCC (44). The expression profiles of miRNA were altered in progressive stages of neoplastic development and the expression level of miR-31 and $-31^{*}$ was frequently downregulated in HGD and EAC, suggesting miR-31 and -375 as novel biomarkers for cancer progression, in BE (45). Other significant miRNAs with dysregulated expression are miR-16-2 and miR-30e, which were associated with shorter overall and disease-free survival in all EC patients and may also be potential prognostic biomarkers (46).

Several studies have demonstrated that miRNAs are consistently detectable in the circulation, as miRNAs have the ability to resist endogenous ribonuclease activity. Moreover, the expression level of serum miRNAs is reproducible and consistent among individuals, thus circulating miRNAs may be used as potential biomarkers for the identification of EC patients. To demonstrate this point, the expression level of miR-21 was upregulated and miR-375 was downregulated in the plasma of ESCC patients compared with healthy controls and the value of the area under the receiver-operating characteristic curve (AUC) was 0.816; patients with a high plasma level of miR-21 have greater vascular invasion and showed a high correlation with recurrence, indicating that circulating miRNAs may be useful as tumor markers for ESCC (47). A panel of 7 serum miRNAs (miR-10a, miR-22, miR-100, miR148b, miR-223, miR-133a and miR-127-3p) were upregulated in ESCC and the area under the ROC curve for the selected miRNAs ranged from 0.817 to 0.949 and could clearly distinguish stage I/II ESCC patients from controls (48). Supporting the role of miRNAs in the circulation, Zhang et al have found that miR-31 levels were significantly higher than controls in 523 serum ESCC samples. Additionally, patients with higher levels of serum miR-31 had a poorer prognosis for relapse-free survival. Those authors concluded that miR-31 is capable of serving as a potential diagnostic and prognostic biomarker for ESCC (49). miR-1322 was significantly highly expressed in ESCC serum samples and can be used to distinguish ESCC from healthy patients (43). Thus, the circulating miRNAs may be used as potential biomarkers not only for diagnostic, but also for prognostic and predictive markers in EC.

\section{The role of miRNAs in invasion and metastasis of EC}

Invasion and metastasis are the two main reasons responsible for cancer-related mortality. The molecular mechanisms of invasion and metastasis are associated with cell-cell and cell-matrix adhesion, with the degradation of the extracellular matrix, and with the initiation and maintenance of early cell growth at the new site. Recently, miRNAs have emerged as post-transcriptional regulators of cancer invasion and metastasis by acting on multiple signaling pathways involved in invasion and metastasis. Analyzing the correlation between miRNA and cell motility and invasiveness in EC is now essential in order to understand the molecular mechanism of cancer invasion and metastasis.

Using a gain-of-function assay, Kano et al (50) revealed that miR-143, miR-145 and miR-133a/b significantly inhibited cell growth and invasion by targeting the FSCN1 gene (51). Matsushima et al proved that miR-10a was downregulated in EC and affected cell migration and invasion by targeting homeobox genes (52). A significant correlation of miR-10b overexpression with strong cell motility and invasiveness by suppression of the tumor suppressor gene KLF4 was observed (53). miR-92a was overexpressed in tumor tissues, which was significantly correlated with the status of lymph node metastasis and TNM stage, and miR-92a enhanced cell migration and invasion at least partially by suppression of CDH1 expression (54). ARTN, a tumor metastasis-related neurotrophic factor, is a direct target of miR-223, and it was overexpressed in EC and negatively associated with miR-223. On further study, it was demonstrated that the overexpression of miR-223 decreased the expression of ARTN and decreased cell migration and invasion (55).

Several studies analyzed the correlation between the expression levels of miRNAs and the clinicopathological parameters of ESCC patients and found that the expression level of miRNAs were correlated with tumor location and lymph node status and recurrence of metastasis, including miR-21, miR-145, miR-205, miR-99b, miR-199a-3p, miR199a-5p, miR-126 and miR-16-2 (46,56-60). Zinc finger E-box-binding (ZEB) proteins ZEB1 and ZEB2 are transcription factors essential in TGF- $\beta$-mediated senescence, epithelial-to-mesenchymal transition (EMT) and cancer stem cell functions, whereas the miR-200 family are negative regulators of ZEBs, and the downregulation of the miR-200 family negatively regulated ZEBs, which were involved in anchorage-independent colony formation, invasion and TGF- $\beta$-mediated EMT in ESCC (61). Transfection with a precursor or inhibitor of miR-205 was found to inhibit cell invasion and migration, whereas knockdown of miR-205 expression in ESCC cells substantially enhanced the expression of zinc finger E-box binding homeobox 2, accompanied by the reduction of E-cadherin (62). Kong et al demonstrated that miR-375 was capable of inhibiting clonogenicity, cell motility and metastasis in ESCC (63). miR-31 was upregulated in ESCC and was shown to promote ESCC migration and invasion, by a mechanism in which miR-31 may interact with tumor suppressor genes of epithelial membrane protein 1 (EMP1), kinase suppressor of ras 2 (KSR2) and regulator of G-protein signaling 4 (RGS4) (49).

\section{The role of miRNAs in the growth of EC}

Tissue homeostasis relies on an intricate balance between cell proliferation and cell death, the latter of which usually occurs in the form of apoptosis. Uncontrolled cell proliferation or 
evasion of apoptosis are common features of malignancy, which are likely to induce unlimited cell growth. Dysregulation of miRNA has been shown to affect tumor growth by influencing the biological processes of cell proliferation and apoptosis in the tumorigenesis of EC.

F-box and WD repeat domain-containing 7 (FBXW7) is a cell cycle regulatory gene whose protein product ubiquitinates positive cell cycle regulators such as c-Myc, cyclin E and c-Jun, and acts as a tumor-suppressor gene. miR-223 expression was significantly higher in cancerous tissues and had an inverse relationship with FBXW7 protein in ESCC (64). miR-375 was able to inhibit clonogenicity, cell proliferation and tumor formation in mice via the downregulation of IGF1R (63). miR-31 was upregulated in ESCC and promoted colony formation through the EMP1, KSR2 and RGS4 genes (49). Ding et al have demonstrated that miR-29c is frequently downregulated in ESCC tissues and cells and it is capable of inhibiting proliferation of ESCC cells in vitro and in vivo by inducing cell cycle $\mathrm{G}(1) / \mathrm{G}(0)$ arrest, mainly through the modulation of cyclin E expression (65). Kan et al found that miR-106b-25 may enhance cell proliferation, inhibit apoptosis, promote cell cycle entry and subsequently promote tumorigenesis in ESCC (66). The mutation of tumor suppressor gene p53 is closely correlated with human cancer. Wild-type p53 is a negative regulator and plays important biological roles in cell cycle regulation, cell differentiation, apoptosis and aging. The p53 network is capable of activating a number of transcriptional targets to inhibit tumor formation. A previous study found that p53 regulated the miR-34 gene family and miR-34 activation is capable of not only inducing cell cycle arrest and cell apoptosis, but also playing a coordinated role in the process of inhibiting cell proliferation (67). p53 is also able to induce the expression of miR-215 and miR-192 and regulate the cell cycle. Downregulation of miR-215 would directly weaken the ability of cell proliferation in EC (68).

Large tumor suppressor homolog 2 (LATS2) belongs to the LATS tumor suppressor family and is capable of regulating the cell cycle and apoptosis. miR-373 and LATS2 showed a negative correlation in ESCC. miR-373 was an oncogene that inhibited the expression of the tumor suppressor gene LATS2 (69). Annexin A1 (ANXA1) mediated apoptosis and inhibited cell proliferation. miR-196a inhibited ANXA1 expression, thus the cell proliferation and inhibition of apoptosis led to EC (70). PDCD4, a new tumor suppressor gene, not only regulated programmed cell death, but also inhibited tumor cell growth. miR-21 was negatively correlated with the expression of PDCD4 in ESCC and may play a role in abnormal proliferation by inhibiting the tumor suppressor gene PDCD4 (58). Transfection with the precursor of miR-145 and miR-133a/b may inhibit cancer cell proliferation by preventing FSCN1 expression (50).

Yuan et al demonstrated that miR-203 was able to inhibit cell proliferation in human ESCC through the $\Delta \mathrm{Np} 63$-mediated signaling pathway and suggested that miR-203 may be used as a therapeutic agent for ESCC (71). Inhibition of miR-17-92 cluster member miR-19a by antisense oligonucleotides (ONs) induced apoptosis and inhibited tumor growth in vivo, probably through targeting tumor necrosis factor- $\alpha$ (TNF- $\alpha$ ) (72). A marked decrease in the level of miR-210 was observed, particularly in poorly differentiated EC, and miR-210 inhibited cancer cell survival and proliferation by inducing cell death and cell cycle arrest in the $\mathrm{G}(1) / \mathrm{G}(0)$ and $\mathrm{G}(2) / \mathrm{M}$ stages (73).

\section{Single nucleotide polymorphisms of miRNAs in EC}

The susceptibility of an individual to environmental risk factors is associated with the incidence and prognosis of the tumor. Single nucleotide polymorphisms (SNPs) are not directly responsible for the incidence of a malignancy but they may make an individual susceptible to particular environmental factors. SNPs of miRNAs could eventually lead to a change in the amount of mature miRNA and new miRNA generation, thus affecting the susceptibility of the tumor (74).

Wang et al studied the genetic association between the SNP (rs11614913) in pre-miRNA-196a and ESCC susceptibility, finding that the homozygote CC of this SNP increased the risk of ESCC compared with the homozygote TT, and the risk was more evident in smokers than non-smokers (75). The SNP rs6505162, which is located in the pre-mir423 region, was associated with a reduced risk of EC. Target genes PABPC1 and FGFR2 of miR-423 were closely correlated with EC; downregulation of PABPC1 was associated with the tumor volume, tumor metastasis and low survival; and upregulation of FGFR2 was associated with the degree of tumor differentiation (76). A strong correlation was found between the $\mathrm{G} / \mathrm{C}$ polymorphism (rs2910164) of miR146a and EC risk in a Han population; the GG genotype may cause a significantly increased risk of EC. In addition, this locus polymorphism was associated with TNM stage in EC patients (77). miR-200b/200c/429 were upregulated in EC and the SNP site rs1045385 (A or C allele) located in the $3^{\prime}$ untranslated region (UTR) of the AP- $2 \alpha$ gene, a target gene of the miR-200b/200c/429 family, may decrease the binding of miR-200b/200c/429 to the 3' UTR of AP-2 $\alpha$, which in turn upregulated the AP- $2 \alpha$ protein expression (78).

\section{The roles of epigenetic regulation of miRNAs in EC}

Pri-miRNA has a 7-methylguanosine cap and poly(A) tail, the same as regular protein-coding genes (79), suggesting that miRNAs can be regulated by epigenetic alterations. Saito et al found that approximately 5\% of human miRNAs were upregulated by the treatment of T24 bladder cancer cells with DNA demethylating agent and histone deacetylase (HDAC) inhibitor (80). DNA hypermethylation in the miRNA 5' regulatory region may be responsible for the downregulation of miRNA in tumors (81).

It was reported that miR-205 was upregulated and miR-10a was downregulated in ESCC cell lines. Further functional analysis revealed that miR-10a was directly regulated by DNA demethylation and the histone deacetylase inhibitor. miR-205 regulated cell invasion and metastasis through the inhibition of E-cadherin expression, in turn affecting epithelial-mesenchymal transition (EMT) (52). Kong et al and Li et al demonstrated that miR-375 was frequently downregulated, caused by hypermethylation of its promoter. miR-375 plays a role in the progression of ESCC by downregulating the target genes IGF1R and PDK1 $(63,82)$. miR-203, miR34b/c, miR-424 and miR-129-2 are embedded in CpG islands, as the promoter region of miR-34a. Chen et al investigated the methylation status of miR-203, miR-34b/c, miR-424 and 
miR-129-2 in ESCC using bisulfite sequencing PCR (BSP) and methylation-specific PCR (MSP) methods, and showed that miR-34a, miR-34b/c and miR-129-2 were frequently downregulated, which are hypermethylated in ESCC (83).

\section{The role of miRNAs in treatment of EC}

Hummel et al examined the impact of chemotherapy on miRNA expression in EC cells and found that 13 miRNAs (miR-199a-5p, miR-302f, miR-320a, miR-342-3p, miR-425, miR-455-3p, miR-486-3p, miR-519c-5p, miR-548d-5p, miR-617, miR-758, miR-766 and miR-1286) were deregulated following treatment with cisplatin or 5 -fluorouracil for 24 or $72 \mathrm{~h}$. Ingenuity Pathway Analysis (IPA) revealed that these miRNAs may target molecular pathways involved in cell survival following chemotherapy (84). miR-141 was the most highly expressed in the cisplatin-resistant ESCC cell lines and the cell viability was significantly increased following cisplatin treatment. The target of miR-141 is YAP1, which is an apoptosis-inducing gene in DNA-damaging agents (85). miR-296 and miR-27a were overexpressed in EC and the knockdown of miR-296 and miR-27a was capable of increasing sensitivity to both P-glycoproteinrelated and $\mathrm{P}$-glycoprotein-non-related drugs, in turn promoting ADR-induced apoptosis in EC cells $(86,87)$. Overexpression of miR-200c significantly correlated with the response to chemotherapy and this effect was associated with the Akt pathway (88). miR-148a upregulation significantly increased sensitivity to chemotherapy in the majority of cells, but the exact mechanisms involved require further study (89). miR-200b/200c/429 were upregulated in endometrial cancer and EC, and their overexpression correlated with resistance to cisplatin treatment (78). miRNA expression profiles in an acquired radioresistant EC line revealed that hsa-let-7a, hsa-miR-185, hsa-miR-141, hsamiR-92b, hsa-miR-22 and hsa-miR-301a were important genes associated with radioresistance, confirming the involvement of miRNAs in radiation resistance in EC (90).

\section{Conclusion}

Although investigations into miRNAs have just begun and the molecular mechanisms of miRNAs in tumorigenesis are not well understood, more evidence that miRNAs are important in the initiation and development of tumors is emerging. Further exploration is required for a better understanding of their roles in the carcinogenesis of EC and for better application in the future. EC-specific miRNAs may eventually constitute useful biomarkers as well as therapeutic targets. Investigations conducted in the field of miRNA are crucial for the personalized treatment of EC.

\section{References}

1. Parkin DM, Bray F, Ferlay J and Pisani P: Global cancer statistics, 2002. CA Cancer J Clin 55: 74-108, 2005.

2. Enzinger PC and Mayer RJ: Esophageal cancer. N Engl J Med 349: 2241-2252, 2003

3. Mishima T, Akagi I, Miyashita M, Ishibashi O, Mizuguchi Y, Tajiri T, et al: Study of microRNA expression profiles of esophageal cancer. J Nippon Med Sch 76: 43, 2009.

4. Lakshmipathy U and Hart RP: Concise review: microRNA expression in multi-potent mesenchymal stromal cells. Stem Cells 26: 356-363, 2008.
5. Calin GA, Sevignani C, Dumitru CD, Hyslop T, Noch E, Yendamuri S, et al: Human microRNA genes are frequently located at fragile sites and genomic regions involved in cancers. Proc Natl Acad Sci USA 101: 2999-3004, 2004.

6. Tsai WC, Hsu PW, Lai TC, et al: MicroRNA-122, a tumor suppressor microRNA that regulates intrahepatic metastasis of hepatocellular carcinoma. Hepatology 49: 1571-1582, 2009.

7. Ferdin J, Kunej T and Calin GA: Non-coding RNAs: identification of cancer-associated microRNAs by gene profiling. Technol Cancer Res Treat 9: 123-138, 2010.

8. Paranjape T, Slack FJ and Weidhaas JB: MicroRNAs: tools for cancer diagnostics. Gut 58: 1546-1554, 2009.

9. Lee Y, Kim M, Han J, Yeom KH, Lee S, Baek SH and Kim VN: MicroRNA genes are transcribed by RNA polymerase II. EMBO J 23: 40512-4060, 2004.

10. Cho WC: MicroRNAs in cancer - from research to therapy. Biochim Biophys Acta 1805: 209-217, 2010.

11. Cai X, Hagedorn CH and Cullen BR: Human microRNAs are processed from capped, polyadenylated transcripts that can also function as mRNAs. RNA 10: 19572-1966, 2004.

12. Lee Y, Ahn C, Han J, Choi H, Kim J, Yim J, Lee J, Provost P, et al: The nuclear RNase III Drosha initiates microRNA processing. Nature 425: 415-419, 2003.

13. Bohnsaek MT, CzaPlinski K and Gorlieh D: Exportin5 is a RanGTP-dependent dsRNA-binding protein that mediates nuclear export of pre-miRNAs. RNA 10: 185-191, 2004.

14. Denli AM, Tops BB, Plasterk RH, Ketting RF and Hannon GJ: Processing of primary microRNAs by the Microprocessor complex. Nature 432: 231-235, 2004

15. Gregory RI and Shiekhattar R: MicroRNA biogenesis and cancer. Cancer Res 65: 3509-3512, 2005.

16. Joshua-Tor L: The Argonautes. Cold Spring Harb Symp Quant Biol 71: 67-72, 2006.

17. Esquela-Kerscher A and Slack FJ: Oncomirs - microRNAs with a role in cancer. Nat Rev Cancer 6: 259-269, 2006.

18. Lee RC, Feinbaum RL and Ambros V: The C. elegans heterochronic gene encodes small RNAs with antisense complementarity to lin-14. Cell 75: 843-854, 1993.

19. Wang B, Doench JG and Novina CD: Analysis of microRNA effector functions in vitro. Methods 43: 91-104, 2007.

20. Calin GA, Dumitru CD, Shimizu M, Bichi R, Zupo S, Noch E, Aldler $\mathrm{H}$, et al: Frequent deletions and down-regulation of micro-RNA genes miR15 and miR16 at 13q14 in chronic lymphocytic leukemia. Proc Natl Acad Sci USA 99: 15524-15529, 2002.

21. Cimmino A, Calin GA, Fabbri M, Iorio MV, Ferracin M, Shimizu M, et al: miR-15 and miR-16 induce apoptosis by targeting BCL2. Proc Natl Acad Sci USA 102: 13944-13949, 2005.

22. Takamizawa J, Konishi H, Yanagisawa K, Tomida S, Osada H, et al: Reduced expression of the let-7 microRNAs in human lung cancers in association with shortened postoperative survival. Cancer Res 64: 3753-3756, 2004.

23. Johnson SM, Lin SY and Slack FJ: The time of appearance of the $C$. elegans let-7 microRNA is transcriptionally controlled utilizing a temporal regulatory element in its promoter. Dev Biol 259: 364-379, 2003.

24. Mott JL, Kobayashi S, Bronk SF and Gores GJ: miR-29 regulates Mcl-1 protein expression and apoptosis. Oncogene 26: 6133-6140, 2007.

25. Gramantieri L, Ferracin M, Fornari F, Veronese A, Sabbioni S, Liu CG, et al: Cyclin G1 is a target of miR-122a, a microRNA frequently down-regulated in human hepatocellular carcinoma. Cancer Res 67: 6092-6099, 2007.

26. Raver-Shapira N, Marciano E, Meiri E, Spector Y, Rosenfeld N, et al: Transcriptional activation of miR-34a contributes to p53-mediated apoptosis. Mol Cell 26: 731-743, 2007.

27. Raver-Shapira N and Oren M: Tiny actors, great roles: microRNAs in p53's service. Cell Cycle 6: 2656-2661, 2007.

28. Wu H, Zhu S and Mo YY: Suppression of cell growth and invasion by miR-205 in breast cancer. Cell Res 19: 439-448, 2009.

29. Nelson KM and Weiss GJ: MicroRNAs and cancer: past, present, and potential future. Mol Cancer Ther 7: 3655-3660, 2008.

30. Lee YS and Dutta A: MicroRNAs in cancer. Annu Rev Pathol 4: 199-227, 2009.

31. Latronico MV, Catalucci D and Condorelli G: MicroRNA and cardiac pathologies. Physiol Genomics 34: 239-242, 2008.

32. He L, Thomson JM, Hemann MT, Hernando-Monge E, Mu D, Goodson S, et al: A miRNA polycistron as a potential human oncogene. Nature 435: 828-833, 2005. 
33. O'Donnell KA, Wentzel EA, Zeller KI, Dang CV and Mendell JT: c-Myc-regulated microRNAs modulate E2F1 expression. Nature 435: 839-843, 2005.

34. Mu P, Han YC, Betel D, Yao E, Squatrito M, Ogrodowski P, et al: Genetic dissection of the miR-17-92 cluster of microRNAs in Myc-induced B-cell lymphomas. Genes Dev 23: 2806-2811, 2009.

35. Zhu S, Si ML, Wu H and Mo YY: MicroRNA-21 targets the tumor suppressor gene tropomyosin 1 (TPM1). J Biol Chem 282: $14328-14336,2007$.

36. Ma L, Teruya-Feldstein J and Weinberg RA: Tumour invasion and metastasis initiated by microRNA-10b in breast cancer. Nature 449: 682-688, 2007.

37. Feber A, Xi L, Luketich JD, Pennathur A, Landreneau RJ, Wu M, et al: MicroRNA expression profiles of esophageal cancer. J Thorac Cardiovasc Surg 135: 255-260, 2008.

38. Guo Y, Chen Z, Zhang L, Shi S, Feng X, et al: Distinctive microRNA profiles relating to patient survival in esophageal squamous cell carcinoma. Cancer Res 68: 26-33, 2008.

39. Mathé EA, Nguyen GH, Bowman ED, Zhao Y, Budhu A, Schetter AJ, Braun R, Reimers M, Kumamoto K, Hughes D, et al: MicroRNA expression in squamous cell carcinoma and adenocarcinoma of the esophagus: associations with survival. Clin Cancer Res 15: 6192-6200, 2009.

40. Kan T and Meltzer SJ: MicroRNAs in Barrett's esophagus and esophageal adenocarcinoma. Curr Opin Pharmacol 9: 727-732, 2009.

41. Maru DM, Singh RR, Hannah C, Albarracin CT, Li YX, Abraham R, Romans AM, Yao H,Luthra MG, Anandasabapathy S, et al: MicroRNA-196a is a potential marker of progression during Barrett's metaplasia-dysplasia-invasive adenocarcinoma sequence in esophagus. Am J Pathol 174: 1940-1948, 2009.

42. Ogawa R, Ishiguro H, Kuwabara Y, Kimura M, Mitsui A, Katada T, Harata K, Tanaka T and Fujii Y: Expression profiling of micro-RNAs in human esophageal squamous cell carcinoma using RT-PCR. Med Mol Morphol 42: 102-109, 2009.

43. Zhang T, Zhao D, Wang Q, Yu X, Cui Y, Guo L and Lu SH: MicroRNA-1322 regulates ECRG2 allele specifically and acts as a potential biomarker in patients with esophageal squamous cell carcinoma. Mol Carcinog: Feb 7, 2012 (Epub ahead of print).

44. Lin RJ, Xiao DW, Liao LD, Chen T, Xie ZF, Huang WZ, Wang WS, Jiang TF, Wu BL, Li EM and Xu LY: MiR-142-3p as a potential prognostic biomarker for esophageal squamous cell carcinoma. J Surg Oncol 105: 175-182, 2012.

45. Leidner RS, Ravi L, Leahy P, Chen Y, Bednarchik B, Streppel M, Canto M, S Wang J, Maitra A, Willis J, et al: The microRNAs, MiR-31 and MiR-375, as candidate markers in Barrett's esophageal carcinogenesis. Genes Chromosomes Cancer 51: 473-479, 2012

46. Hu Y, Correa AM, Hoque A, Guan B, Ye F, Huang J, Swisher SG Wu TT, Ajani JA and Xu XC: Prognostic significance of differentially expressed miRNAs in esophageal cancer. Int J Cancer 128: 132-143, 2011.

47. Komatsu S, Ichikawa D, Takeshita $H$, Tsujiura M, Morimura R, Nagata H, Kosuga T, Iitaka D, Konishi H, Shiozaki A, et al: Circulating microRNAs in plasma of patients with oesophageal squamous cell carcinoma. Br J Cancer 28;105: 104-111, 2011.

48. Zhang C, Wang C, Chen X, Yang C, Li K, Wang J, Dai J, Hu Z, Zhou X, Chen L, et al: Expression profile of microRNAs in serum: a fingerprint for esophageal squamous cell carcinoma. Clin Chem 56: 1871-1879, 2010.

49. Zhang T, Wang Q, Zhao D, Cui Y, Cao B, Guo L and Lu SH: The oncogenetic role of microRNA-31 as a potential biomarker in oesophageal squamous cell carcinoma. Clin Sci (Lond) 121: 437-447, 2011

50. Kano M, Seki N, Kikkawa N, Fujimura L, Hoshino I, Akutsu Y, Chiyomaru T, Enokida H, Nakagawa $\mathrm{M}$ and Matsubara $\mathrm{H}$ : miR-145, miR-133a and miR-133b: Tumor-suppressive miRNAs target FSCN1 in esophageal squamous cell carcinoma. Int J Cancer 127: 2804-2814, 2010.

51. Wu BL, Xu LY, Du ZP, Liao LD, Zhang HF, Huang Q, Fang GQ and Li EM: MiRNA profile in esophageal squamous cell carcinoma: downregulation of miR-143 and miR-145. World J Gastroenterol 17: 79-88, 2011.

52. Matsushima K, Isomoto $\mathrm{H}$, Kohno $\mathrm{S}$ and Nakao K: MicroRNAs and esophageal squamous cell carcinoma. Digestion 82: 138-144, 2010.

53. Tian Y, Luo A, Cai Y, Su Q, Ding F, Chen H and Liu Z: MicroRNA-10b promotes migration and invasion through KLF4 in human esophageal cancer cell lines. J Biol Chem 285: 7986-7994, 2010.
54. Chen ZL, Zhao XH, Wang JW, Li BZ, Wang Z, Sun J, Tan FW, Ding DP, Xu XH, Zhou F, et al: microRNA-92a promotes lymph node metastasis of human esophageal squamous cell carcinoma via E-cadherin. J Biol Chem 286: 10725-10734, 2011.

55. Li S, Li Z, Guo F, Qin X, Liu B, Lei Z, Song Z, Sun L, Zhang HT, You J and Zhou Q: miR-223 regulates migration and invasion by targeting Artemin in human esophageal carcinoma. J Biomed Sci 18: 24, 2011.

56. Hummel R, Hussey DJ, Michael MZ, Haier J, Bruewer M, Senninger $\mathrm{N}$ and Watson DI: miRNAs and their association with locoregional staging and survival following surgery for esophageal carcinoma. Ann Surg Oncol 18: 253-260, 2011.

57. Mori Y, Ishiguro H, Kuwabara Y, Kimura M, Mitsui A, Ogawa R, Katada T, Harata K, Tanaka T, Shiozaki M and Fujii Y: MicroRNA-21 induces cell proliferation and invasion in esophageal squamous cell carcinoma. Mol Med Rep 2: 235-239, 2009.

58. Hiyoshi Y, Kamohara H, Karashima R, Sato N, Imamura Y, Nagai Y, Yoshida N, Toyama E, Hayashi N, Watanabe M and Baba H: MicroRNA-21 regulates the proliferation and invasion in esophageal squamous cell carcinoma. Clin Cancer Res 15: 1915-1922, 2009.

59. Ma WJ, Lv GD, Tuersun A, Liu Q, Liu H, Zheng ST, Huang CG, Feng JG, Wang X, Lin RY, Sheyhidin I and Lu XM: Role of microRNA-21 and effect on PTEN in Kazakh's esophageal squamous cell carcinoma. Mol Biol Rep 38: 3253-3260, 2011.

60. Feber A, Xi L, Pennathur A, Gooding WE, Bandla S, Wu M, Luketich JD, Godfrey TE and Litle VR: MicroRNA prognostic signature for nodal metastases and survival in esophageal adenocarcinoma. Ann Thorac Surg 91: 1523-1530, 2011.

61. Ohashi S, Natsuizaka M, Naganuma S, Kagawa S, Kimura S, Itoh H, Kalman RA, Nakagawa M, Darling DS, Basu D, et al: NOTCH3-mediated squamous cell differentiation program limits expansion of EMT-competent cells that express the ZEB transcription factors. Cancer Res 71: 6836-6847, 2011

62. Matsushima K, Isomoto H, Yamaguchi N, Inoue N, Machida H, Nakayama T, Hayashi T, Kunizaki M, Hidaka S, Nagayasu T, et al: MiRNA-205 modulates cellular invasion and migration via regulating zinc finger E-box binding homeobox 2 expression in esophageal squamous cell carcinoma cells. J Transl Med 9: 30, 2011.

63. Kong KL, Kwong DL, Chan TH, Law SY, Chen L, Li Y, Qin YR and Guan XY: MicroRNA-375 inhibits tumour growth and metastasis in oesophageal squamous cell carcinoma through repressing insulin-like growth factor 1 receptor. Gut 61: 33-42, 2012

64. Kurashige J, Watanabe M, Iwatsuki M, Kinoshita K, Saito S, Hiyoshi Y, Kamohara H, Baba Y, Mimori K and Baba H: Overexpression of microRNA-223 regulates the ubiquitin ligase FBXW7 in oesophageal squamous cell carcinoma. Br J Cancer 106: 182-188, 2012.

65. Ding DP, Chen ZL, Zhao XH, Wang JW, Sun J, Wang Z, Tan FW and Tan XG: miR-29c induces cell cycle arrest in esophageal squamous cell carcinoma by modulating cyclin E expression. Carcinogenesis 32: 1025-1032, 2011.

66. Kan T, Sato F, Ito T, Matsumura N, David S, Cheng Y, Agarwal R, Paun BC, Jin Z, Olaru AV, et al: The miR-106b-25 polycistron, activated by genomic amplification, functions as an oncogene by suppressing p21 and Bim. Gastroenterology 136: 1689-1700, 2009.

67. He L, He X, Lim LP, de Stanchina E, et al: A microRNA component of the p53 tumour suppressor network. Nature 447: 1130-1134, 2007.

68. Wijnhoven BP, Hussey DJ,Watson DI, Tsykin A, Smith CM, et al: microRNA profiling of Barrett's oesophagus and oesophageal adenocarcinoma. Br J Surg 97: 853-861, 2010.

69. Lee KH, Goan YG, Hsiao M, Lee CH, et al: MicroRNA-373 (miR-373) post-transcriptionally regulates large tumor suppressor, homolog2 (LATS2) and stimulates proliferation in human esophageal cancer. Exp Cell Res 315: 2529-2538, 2009.

70. Luthra R, Singh RR, Luthra MG, Li YX, Hannah C, Romans AM, Barkoh BA, Chen SS, Ensor J, Maru DM, et al: MicroRNA-196a targets annexin A1: a microRNA-mediated mechanism of annexin A1 downregulation in cancers. Oncogene 27: 6667-6678, 2008.

71. Yuan Y, Zeng ZY, Liu XH, Gong DJ, Tao J, Cheng HZ and Huang SD: MicroRNA-203 inhibits cell proliferation by repressing $\Delta \mathrm{Np} 63$ expression in human esophageal squamous cell carcinoma. BMC Cancer 11: 57, 2011.

72. Liu M, Wang Z, Yang S, Zhang W, He S, Hu C, Zhu H, Quan L, Bai $J$ and $\mathrm{Xu} \mathrm{N}$ : TNF- $\alpha$ is a novel target of miR-19a. Int J Oncol 38: 1013-1022, 2011. 
73. Tsuchiya S, Fujiwara T, Sato F, Shimada Y, Tanaka E, Sakai Y, Shimizu K and Tsujimoto G: MicroRNA-210 regulates cancer cell proliferation through targeting fibroblast growth factor receptor-like 1 (FGFRL1). J Biol Chem 286: 420-428, 2011.

74. Ryan BM, Robles AI and Harris CC: Genetic variation in microRNA networks: the implications for cancer research. Nat Rev Cancer 10: 389-402, 2010.

75. Wang K, Guo H, Hu H, Xiong G, Guan X, Li J, Xu X, Yang K and Bai Y: A functional variation in pre-microRNA-196a is associated with susceptibility of esophageal squamous cell carcinoma risk in Chinese Han. Biomarkers 15: 614-618, 2010.

76. Ye Y, Wang KK, Gu J, Yang H, et al: Genetic variations in microRNA-related genes are novel susceptibility loci for esophageal cancer risk. Cancer Prev Res (Phila) 1: 460-469, 2008.

77. Guo H, Wang K, Xiong G, Hu H, Wang D, Xu X, Guan X, Yang K and Bai Y: A functional variant in microRNA-146a is associated with risk of esophageal squamous cell carcinoma in Chinese Han. Fam Cancer 9: 599-603, 2010.

78. Wu Y, Xiao Y, Ding X, Zhuo Y, Ren P, Zhou C and Zhou J: A miR-200b/200c/429-binding site polymorphism in the 3 untranslated region of the AP- $2 \alpha$ gene is associated with cisplatin resistance. PLoS One 6: e29043, 2011.

79. Kim VN: MicroRNA biogenesis: coordinated cropping and dicing. Nat Rev Mol Cell Biol 6: 376-385, 2005.

80. Saito Y, Liang G, Egger G, Friedman JM, Chuang JC, Coetzee GA and Jones PA: Specific activation of microRNA-127 with downregulation of the proto-oncogene BCL6 by chromatin-modifying drugs in human cancer cells. Cancer Cell 9: 435-443, 2006.

81. Esteller M: Epigenetics in cancer. N Engl J Med 358: 1148-1159, 2008

82. Li X, Lin R and Li J: Epigenetic silencing of microRNA-375 regulates PDK1 expression in esophageal cancer. Dig Dis Sci 56 : 2849-2856, 2011.
83. Chen X, Hu H, Guan X, Xiong G, Wang Y, Wang K, Li J, Xu X and Yang $\mathrm{K}: \mathrm{CpG}$ island methylation status of miRNAs in esophageal squamous cell carcinoma. Int J Cancer 130: 1607-1613, 2012.

84. Hummel R, Wang T, Watson DI, Michael MZ, Van der Hoek M, Haier J and Hussey DJ: Chemotherapy-induced modification of microRNA expression in esophageal cancer. Oncol Rep 26: 1011-1017, 2011.

85. Imanaka Y, Tsuchiya S, Sato F, Shimada Y, Shimizu K and Tsujimoto G: MicroRNA-141 confers resistance to cisplatininduced apoptosis by targeting YAP1 in human esophageal squamous cell carcinoma. J Hum Genet 56: 270-276, 2011.

86. Zhang H, Li M, Han Y, Hong L, Gong T, Sun L and Zheng X: Down-regulation of miR-27a might reverse multidrug resistance of esophageal squamous cell carcinoma. Dig Dis Sci 55: 2545-2551, 2010.

87. Hong L, Han Y, Zhang H, Li M, Gong T, Sun L, Wu K, Zhao Q and Fan D: The prognostic and chemotherapeutic value of miR-296 in esophageal squamous cell carcinoma. Ann Surg 51: 1056-1063, 2010

88. Hamano R, Miyata H, Yamasaki M, Kurokawa Y, Hara J, Moon JH, Nakajima K, Takiguchi S, Fujiwara Y, Mori M and Doki Y: Overexpression of miR-200c induces chemoresistance in esophageal cancers mediated through activation of the Akt signaling pathway. Clin Cancer Res 17: 3029-3038, 2011.

89. Hummel R, Watson DI, Smith C, Kist J, Michael MZ, Haier J and Hussey DJ: Mir-148a improves response to chemotherapy in sensitive and resistant oesophageal adenocarcinoma and squamous cell carcinoma cells. J Gastrointest Surg 15: 429-438, 2011.

90. Zheng ZF, Su HF, Zou Y, Peng Z and Wu SX: Expression profiles of microRNAs in radioresistant esophageal cell line. Zhonghua Yi Xue Za Zhi 91: 639-642, 2011 (In Chinese). 